\title{
Effects of Opportunities to Learn in Teacher Education on the Development of Teachers' Professional Knowledge of French as a Foreign Language
}

\author{
Marie Evens ${ }^{1 *}$, Jan Elen ${ }^{1}$, and Fien Depaepe ${ }^{12}$ \\ ${ }^{1}$ Centre for Instructional Psychology and Technology, KU Leuven, Leuven, Belgium \\ ${ }^{2}$ ITEC-imec, KU Leuven campus Kulak, Kortrijk, Belgium \\ Email: marie.evens@kuleuven. be
}

\begin{abstract}
An important goal of teacher education (TE) is to improve pre-service teachers' pedagogical content knowledge (PCK), pedagogical knowledge (PK) and content knowledge (CK). It is not always clear what kind of opportunities to learn (OTL) in TE contribute to pre-service teachers' knowledge development. We compared different cohorts $(N=360)$ in TE, and studied the effects of OTL (PCK, PK, CK, and practical experiences) on pre-service teachers' PCK, PK and CK (in the domain of French as a foreign language). Second and third year students outperformed first year students on PCK, PK and CK (measured through quantitative test instruments). Positive effects of PCK OTL on PCK and PK are found, as well as positive effects of CK OTL on CK.
\end{abstract}

Keywords: Teacher cognition; teacher professional knowledge; pedagogical content knowledge; teacher education; foreign language education.

\section{Introduction}

Teachers' professional knowledge is believed to be central to student learning (Connelly, Clandinin, \& He, 1997). Teachers' thinking is claimed to be related to their instructional approaches, and as a consequence, studying teacher knowledge is essential (Verloop, van Driel, \& Meijer, 2001). Research on teachers' professional knowledge mainly follows the influential work of Shulman (1986; 1987), who introduced pedagogical content knowledge (PCK) as the unifying element between general pedagogical knowledge $(\mathrm{PK})$ and content knowledge (CK). Most empirical research on teachers' professional knowledge focuses on the domain of mathematics (König et al., 2016). In this domain research has shown the importance of PCK and CK for instructional quality and student achievement (Baumert et al., 2010; Kunter et al., 2012). Also PK, which is not related to a specific disciplinary domain, has been shown to positively impact instructional quality (König \& Pflanzl, 2016).

It is therefore an important task of teacher education (TE) programs to foster pre-service teachers' PCK, PK and CK. Several studies show the impact of theoretical courses in TE on teachers' professional knowledge development, mainly in the domain of mathematics (e.g., Blömeke, Buchholtz, Suhl \& Kaiser, 2014). According to Schmidt et al. (2011), the following opportunities to learn (OTL) during TE might impact teachers' professional knowledge: courses on CK, courses on PCK, courses on $\mathrm{PK}$, and practical experiences. However, to date, the specific contribution of each of these four sources of OTL to the development of PCK, PK, and CK remains unclear.

The present study focuses on the domain of French as a foreign language in primary TE in Flanders, Belgium. Test instruments are developed to assess PCK, PK and CK in this context. Relying on a crosssectional design, the study aims to investigate (1) whether pre-service teachers in different stages of TE differ in PCK, PK, and CK, and (2) whether specific OTL on PCK, PK, CK and practical experiences have an impact on teachers' professional knowledge. 


\section{Paper Preparation}

\subsection{Conceptualization of Teachers' Professional Knowledge}

Shulman $(1986 ; 1987)$ defined PCK as "that special amalgam of content and pedagogy that is uniquely the province of teachers, their own special form of professional understanding" (Shulman, 1987, p. 8). According to Shulman (1986) PCK consists of two main components: (1) the most regularly taught topics in one's subject area and their most useful forms of representation, and (2) an understanding of what makes the learning of several topics easy or difficult for students. Since Shulman's introduction of PCK, the concept has often been studied, and Shulman's conceptualization has been adapted by several research groups. Grossman (1990) added two components to Shulman's original PCK components, that is, knowledge of curriculum and knowledge of purposes for teaching. Another widely used conceptualization of PCK is the Magnusson model (Magnusson, Krajcik \& Borko, 1999). Magnusson et al. added three PCK components to Shulman's components, that is, teaching orientations, knowledge of curricula, and knowledge of assessment.

Most authors agree that at least content knowledge (CK) and knowledge about pedagogy (PK) play an important role in PCK (Depaepe, Verschaffel, \& Kelchtermans, 2013). According to Shulman (1987), CK comprises the knowledge that should be learned by students. Later definitions of CK mainly focused on the context of mathematics, and claimed that teachers should know the learning content from a more advanced perspective than the level their students should reach (Baumert et al., 2010; Kleickmann et al., 2013). CK differs both from academic knowledge generated in universities, and from everyday knowledge that students learn in school (Krauss et al., 2008).

According to Shulman (1987), PK includes "broad principles and strategies of classroom management and organization that appear to transcend subject matter" (Shulman, 1987, p. 8). While Shulman (1986; 1987) claimed that PCK is a special amalgam of both CK and PK, the growing body of research on teachers' professional knowledge mainly focuses on subject-related knowledge (König, Blömeke, Paine, Schmidt, \& Hsieh, 2011). However, the classroom demands that teachers are confronted with require insights from both a content-specific point of view and a general pedagogical point of view (Fauth, Decristan, Rieser, Klieme, \& Büttner, 2014). More recently, test instruments to assess PK have been developed (König et al., 2011; Voss, Kunter, \& Baumert, 2011). König et al. (2011) developed a largescale test instrument for PK, including the dimensions structure, motivation and classroom management, adaptivity, and assessment. Voss et al. (2011) used the dimensions teaching methods, classroom management, classroom assessment and students' heterogeneity to assess PK (which they called general pedagogical-psychological knowledge). Across definitions, there seems to be agreement that PK comprises at least knowledge on teaching methods and on classroom management, which are the two PK components originally distinguished by Shulman (1987).

In general, conceptualizations of teachers' professional knowledge can be classified as taking either a dynamic perspective or a cognitive perspective (Depaepe et al., 2013). According to the dynamic perspective, teachers' professional knowledge can be described as knowledge in action that is dynamic in nature. Research in this sense mainly exists of small-scale studies that try to capture knowledge in action, for instance by means of interviews and classroom observations. Advocates of a cognitive perspective on teachers' professional knowledge, on the other hand, approach knowledge from a more static point of view, and consider PCK as "the knowledge needed for teaching a specific subject" (Krauss et al., 2008, p. 716). Research in this tradition is mainly conducted on a large scale, using quantitative test instruments to assess teachers' professional knowledge in a generalizable way (Depaepe et al., 2013). Although we completely acknowledge the importance of studying teachers' professional knowledge from a situated point of view, in the present study teachers' professional knowledge is approached from a cognitive point of view. This approach was chosen because systematically studying teachers' professional knowledge on a large scale contributes to the knowledge base on how teachers' professional knowledge develops during TE (König et al., 2016), and to insights in the mutual relations among several knowledge domains and between teachers' professional knowledge and other variables (Stahnke, Schueler, \& Roesken-Winter, 2016). Despite these important potential contributions of the cognitive perspective to the field of teachers' professional knowledge, in the disciplinary domain of 
foreign languages, systematic empirical studies using tests that directly assess PCK, PK and CK barely exist (König et al., 2016).

\subsection{Importance of Teachers' Professional Knowledge}

In the domain of mathematics, some studies empirically showed the importance of teachers' professional knowledge for educational practice from a cognitive point of view. Baumert et al. (2010) found positive effects of teachers' mathematics PCK and CK on instructional quality (measured by means of a student questionnaire) and on student learning gains (measured by means of a mathematics pre- and posttest). PCK was a stronger predictor of instructional quality than CK. Kunter et al. (2013) confirmed the results of Baumert et al. (2010) in a comprehensive model of teacher competence that combined PCK, professional beliefs, work-related motivation and self-regulation in one analysis. Moreover, Kunter et al. showed that teachers' PCK had a positive effect on student motivation (measured by means of an enjoyment questionnaire). Concerning general PK, Voss et al. (2011) found a positive association with student ratings of instructional quality in a study with pre-service teachers. Similarly, König and Pflanzl (2016) showed that in-service teachers' PK was positively correlated with students' perceptions of teaching quality. PK even turned out to be a significant predictor of instructional quality after controlling for TE grades, teacher personality and teaching experience.

\subsection{Development of Teachers' Professional Knowledge in TE}

Most TE institutions offer opportunities to acquire PCK, PK and CK (Blömeke et al., 2008). However, insight into the development of all three categories of teachers' professional knowledge during TE remains limited (Cochran-Smith \& Zeichner, 2005). Until now, some studies described knowledge growth during TE in general, while other studies attempted to explain differences in knowledge growth by focusing on the effects of specific OTL on teachers' professional knowledge.

In the domain of mathematics, some studies focused on documenting the development of teachers' professional knowledge development throughout teacher education in general, either by comparing different cohorts of pre-service teachers (Kleickmann et al., 2013) or by following one cohort throughout their TE in a longitudinal design (Blömeke et al., 2014; Lim-Teo, Chua, Cheang, \& Yeo, 2007). Kleickmann et al. (2013) compared four cohorts: (1) first year secondary pre-service teachers, (2) third year pre-service teachers, (3) pre-service teachers at the end of their induction phase (i.e., the practical phase following on theoretical TE in some countries, such as Germany), and (4) experienced in-service teachers. They only found significant differences between third year and first year pre-service teachers and concluded that deliberative formal learning opportunities provided in the theoretical part of TE are crucial for the development of pre-service teachers' subject-related knowledge, and that teaching experience alone is insufficient. Blömeke et al. (2014) measured mathematics PCK and beliefs on mathematics teaching and learning of one cohort of pre-service teachers' in the first, second and third year of TE. These authors found that pre-service teachers' PCK and beliefs mainly developed between the second and the third year of TE, as PCK courses were mainly programmed between the second and the third year. Lim-Teo et al. (2007) compared primary pre-service teachers' mathematics PCK scores in the beginning of TE with their PCK scores at the end of TE. They found improvement on three components of PCK (i.e., teachers' own understanding of mathematical structure, which is very similar to CK, knowledge of representations and concepts, and knowledge on the cognitive demands of mathematical tasks) while no improvement was found on knowledge of students' learning difficulties and misconceptions.

In addition to the above described studies on the development of teachers' professional knowledge during TE in general, other studies focused on the effects of specific OTL in TE on the development of teachers' professional knowledge in the domain of mathematics. OTL can be defined as "the content to which future teachers are exposed as a part of their teacher preparation programs" (Schmidt et al., 2011, p. 140). Schmidt et al. (2011) distinguish between four main types of OTL in mathematics TE: mathematics $(\mathrm{CK})$, mathematics pedagogy $(\mathrm{PCK})$, general pedagogy $(\mathrm{PK})$, and practical experiences. Concerning CK and PCK OTL most studies found positive learning effects. For instance, Blömeke, Suhl, Kaiser, and Döhrmann (2012) measured OTL by means of a questionnaire asking primary pre-service teachers whether particular learning content was covered in their TE program until then. They found 
that CK OTL explained differences in PCK and CK, while less additional variance was explained by PCK OTL. In a cross-national study, Qian and Youngs (2016) focused on the effects of both the number of CK and PCK courses, and the contents covered in these courses, on pre-service primary school teachers' mathematics PCK and CK. These authors found different effects among countries. The number of CK and PCK courses positively influenced CK and PCK in some countries, while the number of courses on specific topics within CK and PCK had a larger effect (although these effects differed per country). Regarding PK OTL less is known than regarding PCK and CK OTL. From a more situated point of view, Stürmer, Könings, and Seidel (2013) studied in a pretest-posttest design how three TE courses (i.e., three conditions) on PK impacted the development of pre-service teachers' declarative knowledge (related to PK) and their professional vision (i.e., the ability to apply PK, measured by means of a video-based tool). These authors found an improvement in both PK and professional vision in all three conditions and concluded that PK is required as a basis for developing professional vision. Finally, some studies focused on the effects of practical experiences during TE on pre-service teachers' professional knowledge development. Strawhecker (2005) compared the impact of several mathematics methods courses (i.e., content-methods-field condition, methods-field condition, methods-only condition, content-only condition) on the development of primary pre-service teachers' PCK and CK. The conditions that took part in a course with field experiences significantly outperformed the other two conditions. Also in primary TE, Capraro, Capraro, Parker, Kulm, and Raulerson (2005) compared a program including two hours of practical experiences per week with a program including four hours of practical experiences per week. No significant differences on mathematics PCK and CK were found between the two programs. The authors concluded that it is probably not the duration of the practical experiences as such that impacts pre-service teachers' professional knowledge, but rather the quality of the practical experiences.

\subsection{Teachers' Professional Knowledge in the Domain of Foreign Languages}

All of the above described studies are situated in the disciplinary domain of mathematics. It remains an open question whether findings in this domain are applicable to other domains (König et al., 2016). A domain in which large-scale research on teachers' professional knowledge is scarce is the domain of foreign languages. This disciplinary domain is distinct from other domains, among others because in language teaching the content and the medium of instruction are the same. In the foreign language classroom teachers actively use the target language while simultaneously teaching language skills to students (Hlas \& Hildebrandt, 2010).

In one of the first attempts to study teachers' professional knowledge in the domain of foreign language teaching from a cognitive perspective, König et al. (2016) compared the PCK and CK on English as a foreign language, and the PK of two cohorts of pre-service secondary school teachers (i.e., a group at the start of TE and a group in the induction phase). Pre-service teachers in the induction phase significantly outperformed pre-service teachers that were at an earlier stage in TE on PCK and PK. On CK no significant differences were found, which the authors attributed to the absence of CK OTL in the induction phase (in contrast to PCK and PK OTL).

\subsection{The Present Study}

The present study builds on the study of König et al. (2016) in an attempt to study whether research findings on teachers' professional knowledge from the domain of mathematics also apply to the domain of foreign languages. It focuses on the differences in PCK, PK and CK among different cohorts in TE. The present study differs from König et al. (2016) in at least the following ways. Firstly, while König et al. (2016) compared the results of two cohorts of students without focusing on the effects of specific OTL, the present study tries to explain differences among cohorts with additional analyses on the effects of specific OTL in TE. Secondly, the study is situated in the context of primary TE in Flanders (Belgium), that consists of three years of study, in which pre-service teachers are educated to become generalists (teaching several courses such as French, Dutch, mathematics, etc.). Hence, the study investigates whether the results of König et al. (2016) also apply in a different context.

The present study is guided by the following research questions (RQs): 
(1) Are there differences in French PCK, CK and general PK among first, second and third year pre-service primary school teachers, after controlling for prior education (academic versus non-academic secondary education, and whether or not secondary education focused on languages)?

(2) What is the impact of OTL in primary TE (concerning PCK, PK, CK, and practical experiences) on pre-service primary school teachers' professional knowledge (French PCK, $\mathrm{CK}$, and general PK), after controlling for prior education (academic versus nonacademic secondary education, and whether or not secondary education focused on languages)?

\section{Methods}

\subsection{Participants and Context}

The study took place in Flanders, Belgium. In Flemish primary TE, students are prepared to be generalists, that is, to teach all courses that are part of primary education. French is one of the courses that is taught in primary education because it is the official language in Wallonia, the southern half of Belgium. More specifically, French is compulsory starting from the fifth grade. Each TE institution can decide how much time they provide for French subject matter (i.e., CK), French methods (i.e., PCK), and general pedagogy (i.e., PK). To become a teacher, students have to complete a bachelor program consisting of 180 ECTS credits $^{1}$, of which at least 45 credits are practice-related (i.e., internships). TE programs take three years of study.

In total, 356 pre-service teachers took part in the study. The participants were recruited from all three years of study in two Flemish TE institutions. As there is a strong selection between the first and the second year of TE, those first year students that did not move on to the second year in the next academic year were excluded from the dataset to prevent selection effects. The adjusted total number of participants is 313 . The average age is 20.31 years old $(S D=3.48)$. Table 1 provides an overview of the most important background characteristics of the participants. The number of females is much higher than the number of males, which is normal for TE in Flanders. Concerning prior education, two measures were used. Firstly, the participants' educational track in secondary education was taken into account. In Flemish secondary education students can choose between an academic, a technical, a vocational and an artistic track. In the present study a distinction is made between the academic track and all other tracks. Secondly, we looked at whether or not participants studied modern languages in secondary education (which is a field of study in the academic track). Some participants indicated that they were bilingual or that they had dyslexia. These students were excluded from the analyses as they might have been largely (dis)advantaged when taking part in the study.

Table 1. Cross table of cohort and background characteristics.

\begin{tabular}{|c|c|c|c|c|}
\hline Background characteristics & $\begin{array}{l}\text { First } \\
\text { year }\end{array}$ & $\begin{array}{l}\text { Second } \\
\text { year }\end{array}$ & $\begin{array}{l}\text { Third } \\
\text { year }\end{array}$ & Total \\
\hline Total number of participants & 87 & 136 & 90 & 313 \\
\hline Number of females & 71 & 116 & 82 & 269 \\
\hline Number of participants from Institution 1 (as opposed to Institution 2) & 38 & 103 & 52 & 193 \\
\hline $\begin{array}{l}\text { Number of participants with academic prior education (as opposed to } \\
\text { prior education in other tracks) }\end{array}$ & 49 & 62 & 44 & 155 \\
\hline Number of participants with prior education in languages & 14 & 16 & 17 & 47 \\
\hline Number of bilingual participants & 6 & 5 & 7 & 18 \\
\hline Number of participants with dyslexia & 3 & 0 & 0 & 3 \\
\hline
\end{tabular}

${ }^{1}$ One ECTS-credit equals 25 to 30 hours of study. 


\subsection{Instruments}

Three quantitative paper-and-pencil instruments were developed to assess PCK, CK, and PK. Following a cognitive view on teachers' professional knowledge, the instruments focused on declarative knowledge. Sample items of all three instruments are displayed in Figure 1. The items of the PCK and PK instruments were formulated in Dutch, whereas the CK items were formulated in French. We consider the ability to understand French questions as a part of CK. In order to avoid participants' CK to influence their ability to understand the PCK and PK instrument, the latter two instruments were administered in Dutch. Several pilot studies were conducted with previous versions of the instruments (with educational sciences students and pre-service teachers), leading to the final set of items.

The PCK instrument focuses on oral interaction (OI), one of the five skills that are part of the Flemish attainment targets (along with listening, reading, speaking, and writing) of French (and other languages) in all levels of education. In OI production and reception alternate. When one person is speaking, the other is already forecasting the remainder of the message and preparing a response. This is different from the skill 'speaking', in which speakers give a monologue or take part in a dialogue, in which they know beforehand what the other person is about to say (Council of Europe, n.d.). OI has become increasingly important since communicative and task-based language teaching are gaining ground (González Humanez \& Arias, 2009; Herazo Rivera, 2009), but educational practice on oral skills is lagging behind (Kwakernaak, 2009). Before developing the instruments, interviews were conducted with 13 primary school teachers and 10 French teacher educators to explore the current approaches and the needs concerning OI. In general, primary school teachers felt not well prepared to teach OI, while OI increasingly becomes part of manuals. This finding was confirmed by French teacher educators, indicating that the available time for French in TE is mainly used for other topics than for PCK on OI. The following dimensions are covered in the PCK instrument: knowledge of student understanding, knowledge of educational representations, knowledge of curriculum, and knowledge of assessment. Several considerations were taken into account when choosing these four domains: theoretical models on PCK (Grossman, 1990; Magnusson et al., 1999; Shulman, 1987), practical experiences of two teacher educators of French in primary education who assisted in developing the instruments, the curriculum of Flemish primary education, and available literature on French language teaching and learning in primary education, such as Kwakernaak (2009), Sercu, Vyncke, and Peters (2003), Theissen, Hiligsmann, Rasier, and Klein (2015). There were 10 short-answer items in the instrument, each having four subitems. Three items focused on knowledge of students' understanding, four items on knowledge about educational representations, four items on knowledge of curriculum, and two items on knowledge of assessment. Of these items, two focused on both knowledge of student understanding and educational representations. For instance, one item asked why dyslectic students would have difficulty with OI, and how teachers could support these students.

The CK instrument consisted of eight main items, each divided into four to ten short-answer subquestions. The test focused on grammar and vocabulary. The CK instrument is developed by French teacher educators and reviewed by educational researchers. The level of difficulty of the test is situated at level A2 of the Common European Framework of Reference (Council of Europe, n.d.). This is one level higher than the level that students are expected to reach at the end of primary education (i.e., level A1). The level that pre-service teachers are expected to reach at the end of TE is B1 for productive skills and B2 for receptive skills. A lower level was chosen for the CK test to ensure enough variation. Low scores on B1/B2 tests can be expected because Martens and Voets (2012) showed that the level of Flemish pre-service primary school teachers' French is very low.

The PK instrument focused on the following content domains: lesson goals, student characteristics, classroom management, teaching methods, feedback, and evaluation. These content domains are based on the PK models of König et al. (2011) and Voss et al. (2011). These two instruments were not used in the present study because they focus on secondary education, while the present study deals with primary education. The PK instrument used in the present study was reviewed by academic educational researchers and teacher educators. The test consisted of 16 items, each consisting of five short-answer sub-items. 


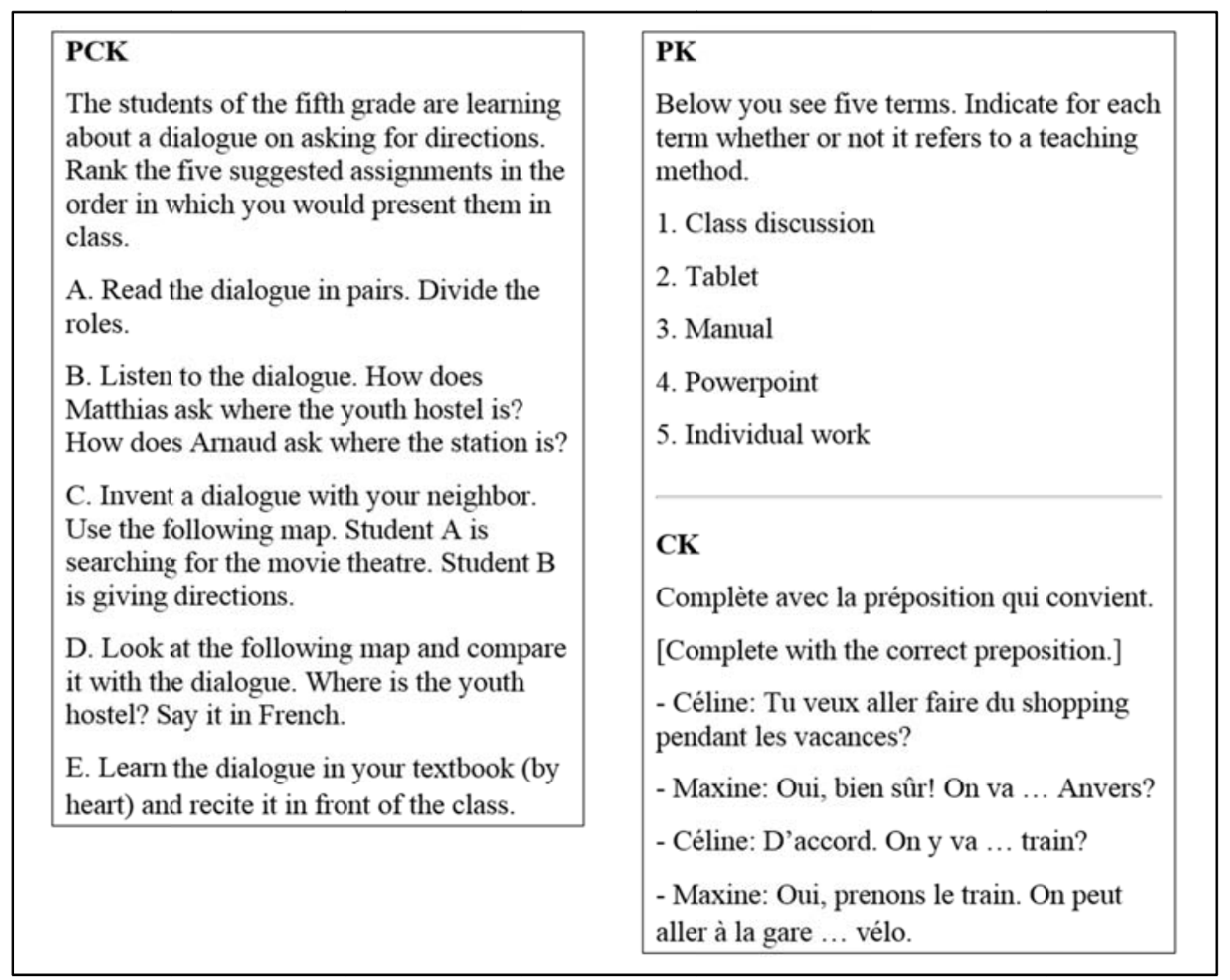

Figure 1. Sample items of the PCK, PK, and CK instruments.

The instruments' reliability was tested in two ways. Firstly, interrater reliability was calculated. Twenty tests were scored by two raters with the aid of a correction key, based on the available literature. All answers were rated as correct or incorrect. Cohen's k of .85 for CK, .76 for PCK, and .84 for PK were found, indicating good agreement for PCK and very good agreement for PK and CK (Altman, 1999). The differences in rating between the two raters were discussed and one rater continued rating the rest of the sample. Secondly, to measure internal consistency Cronbach's $\alpha$ was calculated for all tests. For PCK an $\alpha$ of .59 was found, for PK $\alpha$ was .74, and for CK $\alpha$ was .88. When making the comparison with the 0.7 cutoff score, the reliability statistics show good internal consistency of the PK and CK instrument, and somewhat lower internal consistency of the PCK instrument.

Four types of OTL were taken into account: the number of course hours on French CK, French PCK, and general PK, and the number of internship days pre-service teachers completed. Based on the curricula and the timetables of the participating institutions the number of hours/days was counted starting from the beginning of the first year until the moment of data collection (i.e., in February-March, which is in the beginning of the second half of the academic year). OTL were calculated on the institutional level, not on the individual level, because in the participating institutions all courses on PK and French PCK and CK, and all internships are part of a compulsory curriculum without optional courses. In both participating institutions, in at least one course French PCK and CK were combined. The teacher educators that are responsible for these courses were asked to clarify the distribution of PCK and CK of these courses. In both institutions the French teacher educators indicated that two thirds of the time was allocated to CK, and one third to PCK. Hence, the number of hours for PCK and CK were calculated as respectively one third and two thirds of the available time for these French PCKCK courses. Another possibility to measure OTL would have been to count completed credits, but this option was not preferred because data collection took place a few weeks after the start of the second semester. It would be impossible to take these weeks into account when counting completed credits, while at the same time the learning opportunities that the participants engaged in during these weeks would very likely impact their knowledge. 
Some questions on participants' prior education were also included. Participants had to indicate the educational track (general track, technical track, vocational track, or artistic track) and the field of study they followed in the last year of secondary education.

\subsection{Procedure}

The paper-and-pencil tests were administered in the participating institutions. All students from the classes that were assigned to participation in the study by their teacher educators were invited to take part. The participants had 90 minutes to complete all instruments. The data collection sessions were guided by one researcher and one French teacher educator. All participants signed informed consent documents stating the objectives of the study, and confirming that their participation was voluntary. At the start of the subsequent academic year the participating French teacher educators were asked to provide lists of the first year students that passed on to the second year, in order to filter out those students that did not pass.

\subsection{Analyses}

For RQ1 (Are there differences in French PCK, CK, and general PK among first, second, and third year pre-service primary school teachers, after controlling for prior education?) MANCOVA was performed. Participants' cohort was used as the independent variable (first, second, or third year), and PCK, PK, and CK scores were used as dependent variables. The two variables on prior education (whether or not participants studied modern languages in secondary education, and whether or not they followed a field of study in the academic track) were used as covariates. To study the results of the MANCOVA in more detail, follow-up univariate ANCOVAs were performed for PCK, PK, and CK separately, in which the same independent variables and covariates were used as in the MANCOVA. Simple contrast analyses were performed to find out the exact differences among groups.

RQ2 (What is the impact of OTL in primary TE (concerning PCK, PK, CK, and practical experiences) on pre-service primary school teachers' professional knowledge (French PCK, CK, and general PK), after controlling for prior education?) was studied through multiple regression analyses. PCK, PK, and CK were used as criteria. The predictors were entered in two models to find out the additional explained variance of the OTL. The first model contained two variables on prior education. The second model also contained the four variables on OTL (number of hours on French PCK, CK, and general PK courses, and number of internship days).

\section{$4 \quad$ Results}

Table 2 shows descriptive statistics related to PCK, PK, and CK for each participating TE institution. On all three knowledge domains, mean scores in the first year are smaller than mean scores in the second and third year. The differences between the second and the third year are rather small. Participants from institution 1 perform on average better on PCK and PK than participants from institution 2. The opposite applies to CK.

Table 2. Descriptive statistics related to PCK, PK, and CK scores.

\begin{tabular}{c|c|c|c|c|c|c|c}
\hline & Institution & Cohort & $N$ & $M$ & $S D$ & Min. & Max. \\
\hline \multirow{3}{*}{ PCK } & \multirow{2}{*}{1} & First year & 37 & 44.59 & 8.34 & 26.25 & 67.50 \\
\cline { 3 - 8 } & & Second year & 103 & 50.23 & 10.12 & 26.25 & 85.00 \\
\cline { 3 - 8 } & & Third year & 52 & 49.23 & 11.37 & 12.50 & 68.75 \\
\cline { 2 - 8 } & 2 & First year & 48 & 41.51 & 8.02 & 26.25 & 57.50 \\
\cline { 2 - 8 } & & Second year & 33 & 44.55 & 10.28 & 27.50 & 72.50 \\
\cline { 2 - 8 } & & Third year & 38 & 46.78 & 8.46 & 33.75 & 68.75 \\
\hline \multirow{2}{*}{ PK } & \multirow{2}{*}{1} & First year & 37 & 60.81 & 8.14 & 46.25 & 87.50 \\
\cline { 3 - 8 } & & Second year & 103 & 67.75 & 8.54 & 51.25 & 85.00 \\
\hline
\end{tabular}




\begin{tabular}{c|c|c|c|c|c|c|c}
\hline \multirow{4}{*}{} & & Third year & 52 & 66.80 & 9.31 & 46.25 & 87.50 \\
\cline { 2 - 8 } & 2 & First year & 49 & 59.36 & 7.17 & 43.75 & 75.00 \\
\cline { 2 - 8 } & & Second year & 33 & 63.11 & 7.42 & 41.25 & 73.75 \\
\hline \multirow{2}{*}{ CK } & \multirow{2}{*}{1} & Third year & 38 & 64.48 & 7.51 & 46.25 & 77.50 \\
\hline & & First year & 37 & 40.33 & 14.63 & 16.95 & 73.73 \\
\cline { 3 - 8 } & Second year & 103 & 51.13 & 14.35 & 15.25 & 84.75 \\
\cline { 3 - 8 } & Third year & 52 & 53.05 & 15.72 & 16.10 & 90.68 \\
\hline \multirow{2}{*}{2} & First year & 48 & 49.26 & 17.44 & 16.95 & 84.75 \\
\hline & & Second year & 33 & 55.01 & 11.60 & 37.29 & 77.12 \\
\hline & & Third year & 37 & 55.96 & 12.62 & 36.44 & 83.05 \\
\hline
\end{tabular}

In Table 3 an overview of OTL in the participating institutions is displayed. In both institutions, the CK and especially PCK OTL are very low in comparison with PK OTL. No more PCK and CK OTL are provided in the third year in both institutions. Especially the number of days in practice differs largely between the second and the third year. In comparison to institution 1, institution 2 provides a smaller number of hours on PCK, and a larger number of hours on PK and CK.

Table 3. Number of OTL concerning PCK, PK, CK, and practical experiences in both participating institutions.

\begin{tabular}{c|c|c|c|c|c}
\hline Institution & Cohort & $\begin{array}{c}\text { PCK OTL } \\
\text { (hours) }\end{array}$ & $\begin{array}{c}\text { PK OTL } \\
\text { (hours) }\end{array}$ & $\begin{array}{c}\text { CK OTL } \\
\text { (hours) }\end{array}$ & $\begin{array}{c}\text { OTL regarding practical } \\
\text { experiences (days) }\end{array}$ \\
\hline \multirow{2}{*}{1} & First year & 1.33 & 32.50 & 2.67 & 12.00 \\
\cline { 2 - 6 } & Second year & 15.16 & 83.50 & 30.34 & 33.00 \\
\cline { 2 - 6 } & Third year & 15.16 & 83.50 & 30.34 & 64.00 \\
\hline \multirow{2}{*}{2} & First year & .00 & .44 & 12.00 & 13.00 \\
\cline { 2 - 6 } & Second year & 9.33 & 88.00 & 46.67 & 41.00 \\
\cline { 2 - 6 } & Third year & 9.33 & 100.00 & 46.67 & 82.00 \\
\hline
\end{tabular}

The following paragraphs describe the results concerning RQ1 (Are there differences in French PCK, CK, and general PK among first, second, and third year pre-service primary school teachers, after controlling for prior education?). Firstly, assumptions for performing MANCOVA were checked. None of them were violated. Results of the MANCOVA are displayed in Table 4. The difference by cohort was significant.

Table 4. Results of the MANCOVA.

\begin{tabular}{c|c|c|c|c|c}
\hline & $V$ & $F$ & $d f_{\text {hypothesis }}$ & $d f_{\text {effect }}$ & $p$ \\
\hline Academic prior education & .19 & 22.68 & 3.00 & 300.00 & $<.001$ \\
\hline Prior education with modern languages & .02 & 2.43 & 3.00 & 300.00 & $<.001$ \\
\hline Cohort & .20 & 10.83 & 6.00 & 602.00 & $<.001$ \\
\hline
\end{tabular}

Concerning PCK, after controlling for prior education, participants' cohort was significantly related to their performance, with a medium effect size, $F(2,306)=14.85, p<.001, \eta^{2}{ }_{p}=.08$. Of the two covariates, whether or not participants studied an academic field of study had a significantly positive impact on their PCK, with a medium effect size, $F(1,306)=14.85, p<.001, \eta^{2}{ }_{\mathrm{p}}=.05$, while prior education in modern languages did not significantly impact PCK, $F(1,306)=.08, p=.79$. Simple contrast analyses showed significant differences with medium effect sizes between the first and the second year $(p<.001, d=.64)$, between the first and the third year $(p<.001, d=.57)$, but not between the second and the third year $(p=.52)$.

With regard to PK, after controlling for prior education, participants' cohort was significantly related to their performance, with a large effect size, $F(2,307)=23.44, p<.001, \eta^{2}{ }_{p}=.13$. Again, academic prior education had a positive impact, with a medium effect size, $F(1,307)=25.91, p<.001, \eta^{2}{ }_{\mathrm{p}}=.08$. 
Prior education in modern languages did not significantly impact PK, $F(1,307)=.001, p=.98$. Simple contrast analyses showed significant differences with large effect sizes between the first and the second year $(p<.001, d=.84)$, between the first and the third year $(p<.001, d=.70)$, but not between the second and the third year $(p=.25)$.

Regarding CK, after controlling for prior education, a significant connection with participants' cohort was found, with a medium effect size, $F(2,305)=14.50, p<.001, \eta^{2} \mathrm{p}=.09$. A significant positive impact of both covariates was found, that is, a large effect of academic prior education, $F(1,305)=$ $52.80, p<.001, \mathrm{n}^{2} \mathrm{p}=.15$, and a small effect of prior education in modern languages, $F(1,305)=6.59, p$ $=.01$, partial $\eta^{2}=.02$. Simple contrast analyses showed significant differences with medium effect sizes between the first and the second year $(p<.001, d=.40)$, between the first and the third year $(p<.001$, $d=.57)$, but not between the second and the third year $(p=.47)$.

The findings concerning RQ2 (What is the impact of OTL in primary TE (concerning PCK, PK, CK, and practical experiences) on pre-service primary school teachers' professional knowledge (French PCK, CK, and general PK), after controlling for prior education?) are presented in the following paragraphs. Assumptions for performing multiple regression were checked. The assumptions of linearity, independency of errors, homoscedasticity, and normality were met. However, the assumption of avoiding too high levels of multicollinearity among predictors was violated, which is problematic because it leads to untrustworthy $b$-values, it limits the size of $R$, and it makes it difficult to assess the individual importance of predictors (Field, 2013). When looking at the variance inflation factor (VIF) levels, especially PK OTL seemed to correlate very highly with all other predictors (OTL on PCK, CK, and practical experiences). Therefore, we decided to exclude PK OTL from the regression models. This adaptation led to sufficient VIF levels to no longer consider multicollinearity as a threat for the regression model, as no VIF levels were higher than 10, and the average VIF was not substantially higher than one (Bowerman \& O'Connell, 1990). ${ }^{2}$

Concerning PCK, the model only containing the variables on prior education explained $5 \%$ of the variance, $F(2,305)=7.78, p=.001$. The second model, also including OTL as predictors, explained $17 \%$ of the variance of PCK, $F(5,302)=11.93, p<.001$. The regression coefficients can be found in Table 5 . PCK OTL had a significantly positive impact on PCK. Furthermore, participants with a background in academic secondary education significantly outperformed participants with other prior education.

Table 5. Results of multiple regression analyses with PCK as criterion.

\begin{tabular}{|c|c|c|c|c|c|c|c|c|}
\hline & \multicolumn{4}{|c|}{ Model 1} & \multicolumn{4}{|c|}{ Model 2} \\
\hline & $B$ & $\mathrm{SE}(B)$ & $\beta$ & $t$ & $B$ & $\mathrm{SE}(B)$ & $\beta$ & $t$ \\
\hline (Constant) & 44.84 & .80 & & $56.29 * * *$ & 40.24 & 1.35 & & $29.86^{* * *}$ \\
\hline Academic prior education & 4.25 & 1.25 & .21 & $3.40^{* *}$ & 4.91 & 1.19 & .24 & $4.15^{* * *}$ \\
\hline Prior education with modern languages & .66 & 1.76 & .023 & .38 & 1.33 & 3.67 & .05 & .80 \\
\hline PCK OTL & & & & & .67 & .11 & 41 & $5.92 * * *$ \\
\hline CK OTL & & & & & -.10 & .07 & -.13 & -1.45 \\
\hline OTL regarding practical experiences & & & & & .01 & .04 & .02 & .18 \\
\hline
\end{tabular}

Regarding PK, the first model (only including the variables on prior education) explained $7 \%$ of the variance, $F(2,306)=11.04, p<.001$. The second model, that also included OTL as predictors, explained $23 \%$ of the variance, $F(5,303)=18.37, p<.001$. Table 6 shows the regression coefficients. The variables that impacted PCK also significantly impacted PK, that is, academic prior education and PCK OTL.

\footnotetext{
${ }^{2}$ Separate analyses with PK OTL and the variables concerning prior education as predictors and PCK, PK and CK as criteria showed a significant impact of PK OTL on PCK, $\beta=.21, t=3.88, p<.001, \mathrm{PK}, \beta=.28, t=5.30, p$ $<.001$, and CK, $\beta=.26, t=5.19, p<.001$. These results are not included in the results section because of the high correlation of PK OTL with other predictors.
} 
Table 6. Results of multiple regression analyses with PK as criterion.

\begin{tabular}{|c|c|c|c|c|c|c|c|c|}
\hline & \multicolumn{4}{|c|}{ Model 1} & \multicolumn{4}{|c|}{ Model 2} \\
\hline & $B$ & $\mathrm{SE}(B)$ & $\beta$ & $t$ & $B$ & $\mathrm{SE}(B)$ & $\beta$ & $t$ \\
\hline (Constant) & 62.38 & .68 & & $91.57 * * *$ & 57.03 & 1.11 & & $51.22^{* * *}$ \\
\hline Academic prior education & 4.51 & 1.07 & .26 & $4.23^{* * *}$ & 5.22 & .98 & .30 & $5.33^{* * *}$ \\
\hline Prior education with modern languages & .12 & 1.50 & .01 & .08 & .65 & 1.38 & .03 & .47 \\
\hline PCK OTL & & & & & .65 & .09 & .46 & $6.94^{* * *}$ \\
\hline CK OTL & & & & & -.04 & .05 & -.07 & -.79 \\
\hline OTL regarding practical experiences & & & & & -.01 & .03 & -0.2 & -.20 \\
\hline
\end{tabular}

The first model, that only included variables on prior education, explained $21 \%$ of the variance of CK. The second model, also including the variables on OTL, explained $29 \%$ of the CK variance. The regression coefficients can be found in Table 7. CK OTL had a significant impact on CK scores. Furthermore, participants with a background in the academic track of secondary education significantly outperformed participants from other educational tracks, and participants with prior education in modern languages significantly outperformed participants with other educational backgrounds.

Table 7. Results of multiple regression analyses with CK as criterion.

\begin{tabular}{c|c|c|c|c|c|c|c|c}
\hline & \multicolumn{4}{|c|}{ Model 1 } & \multicolumn{4}{c}{ Model 2 } \\
\hline & $B$ & $\mathrm{SE}(B)$ & $\beta$ & $t$ & $B$ & $\mathrm{SE}(B)$ & $\beta$ & $t$ \\
\hline (Constant) & 44.36 & 1.10 & & $40.24^{* * *}$ & 35.52 & 1.89 & & $18.80^{* * *}$ \\
\hline Academic prior education & 11.12 & 1.71 & .37 & $6.49^{* * *}$ & 11.77 & 1.65 & .39 & $7.15^{* * *}$ \\
\hline Prior education with modern languages & 6.79 & 2.40 & .16 & $2.83^{* *}$ & 6.29 & 2.31 & .15 & $2.73^{* *}$ \\
\hline PCK OTL & & & & & .22 & .16 & .09 & 1.41 \\
\hline CK OTL & & & & & .26 & .09 & .24 & $2.90^{* *}$ \\
\hline OTL regarding practical experiences & & & & & -.02 & .05 & -.04 & -.45 \\
\hline
\end{tabular}

Note. ${ }^{*}=p<.05, * *=p<.01, * * *=p<.001$

\section{Discussion and Conclusion}

The present study examined differences in French PCK and CK, and general PK among three cohorts in primary TE (i.e., pre-service teachers from the first, second, and third year of study) in a cross-sectional way. More specifically, the following RQs were addressed: (1) Are there differences in French PCK, CK, and general PK among first, second, and third year pre-service primary school teachers, after controlling for prior education? (2) What is the impact of OTL in primary TE (concerning PCK, PK, CK, and practical experiences) on pre-service primary school teachers' professional knowledge (French PCK, CK, and general PK), after controlling for prior education?

Concerning RQ1, there are two main findings. Firstly, on all three knowledge domains (PCK, PK, and CK) a significantly better performance of second and third year students in comparison with first year students was found, with medium to large effect sizes. This finding provides evidence for the importance of TE for the development of teachers' professional knowledge. Although the present study did not use a longitudinal design, there is evidence that the courses and practical experiences that the students completed during the first year and the first semester of the second year were positively related to their declarative knowledge development. These findings indicate that the findings by Blömeke et al. (2014), Kleickmann et al. (2013), König et al. (2016), and Lim-Teo et al. (2007), showing improvement in preservice teachers' professional knowledge during TE, also apply to the context of the present study. Although it is a positive finding that second and third year students have more knowledge than first year students, the observed differences in PCK, PK, and CK are not very large. In most Flemish TE institutions, there are no more courses on French CK and PCK in the third year of TE. The finding that the differences in professional knowledge between first year students and more advanced students are small is in line with the results of a very practice-oriented study conducted by French teacher educators in the Flemish context. This study concluded that students do not reach the necessary French CK level 
at the end of TE because of low entrance performances and insufficient time for French in TE (Martens \& Voets, 2012). The present study showed that this conclusion might also count for French PCK.

Secondly, between second and third year students no significant differences were found. This finding could be explained by the fact that, in both participating institutions, all courses on French PCK and CK, and most courses on PK, are scheduled in the first one and a half year. This would mean that these courses on PCK, PK, and CK have an important impact on pre-service teachers' knowledge development. The importance of courses in TE is further investigated in RQ2.

Regarding RQ2, there are findings concerning OTL on PCK, CK, and practical experiences. Firstly, PCK OTL had a significant impact on PCK and PK. The more courses pre-service teachers had on French PCK, the better their test performance on PCK and PK. This corresponds with previous research in mathematics (Blömeke et al., 2012; Qian \& Youngs, 2016). The impact of PCK OTL on PK scores indicates that pre-service teachers were able to transfer the general knowledge they gained in PCK courses to other domains. This finding is very interesting because, to the best of our knowledge, prior research has not yet studied the impact of PCK courses on PK. This finding stresses the importance of PCK courses in TE, as these courses seem to benefit not only the development of subject-related knowledge. On the other hand, no effect of PCK OTL on CK scores was found. This finding does not fully match previous research by Blömeke et al. (2012) and Qian and Youngs (2016) who found positive effects of PCK OTL on CK (in some countries). Several possible explanations for this finding can be put forward. A first possibility is that French PCK courses in the participating institutions put more emphasis on topics that are more closely related to PK than on topics that are related to CK. This could also be an explanation for the finding that PCK OTL did have an impact on PK. A possible reason why PK-related topics would be emphasized more in TE institutions is that PK plays a particularly important role when teachers are prepared to become generalists who teach in several grade levels (Blömeke et al., 2008), such as in Flemish primary TE. A second possible reason is that in the domain of foreign languages the link between PCK and PK might be closer than the link between PCK and CK. Similarly, König et al. (2016) showed that correlations between PCK and PK were higher than between PCK and CK in pre-service teachers of English as a foreign language. At the same time, correlations between PCK and CK are higher in most studies on mathematics (Depaepe et al., 2013).

Secondly, CK OTL had a positive effect on CK and no effect on PCK and PK. The effect on CK corresponds with Blömeke et al. (2012) and Qian and Youngs (2016). Courses on CK seem to succeed in improving pre-service teachers' CK. The absence of an effect of CK OTL on PK is rather logical as CK and PK are more distant from each other in Shulman's (1987) amalgam hypothesis (König et al., 2016). The finding that CK OTL did not impact PCK is more surprising, and does not correspond to the results of Blömeke et al. (2012) and Qian and Youngs (2016). A first possible reason is that the items in the PCK instrument are more closely related to PK than to CK. A second possibility is that, as mentioned before, in the domain of foreign languages there might be a closer link between PCK and PK than between PCK and CK.

Thirdly, practical experiences did not significantly impact the assessed knowledge domains. The internships that the pre-service teachers completed did not improve their performance on the test instruments. Regarding PCK and CK, this finding is not very surprising because students only taught a few French lessons during their internships. Concerning PK, the result is less as anticipated, as one might expect that pre-service teachers also improve their PK by teaching other courses than French (e.g. mathematics, first language, etc.). It might be that internships are too short to develop teachers' professional knowledge. For instance, research has shown that beginning teachers are much more focused on self-concerns (i.e., concerns about survival as a teacher), and that the task of teaching and their impact on students only start to concern them when they gain more teaching experience (Pigge \& Marso, 1997). From this point of view, it is understandable that knowledge development increases when teachers become more experienced in teaching practice, and shift away from their self-concerns. Another possible explanation for the absence of an effect of practical experiences lies in the nature of the test instruments. As the present study takes a cognitive point of view, only declarative knowledge is tested. This kind of knowledge probably also plays a major role in courses in TE. Internships, on the other hand, are very likely to lead to other learning results, such as procedural knowledge or the application of declarative knowledge. Hence, the lack of an effect of practical experiences does not mean that internships are not useful. Finally, a remark should be made concerning the scheduling of the largest internship in the participating institutions. As data collection took place in the beginning of the second semester of the academic year, none of the participants had already completed the largest internship that was part of the teacher training program. In both institutions this internship was scheduled at the end of the second semester of the third year. It is possible that this internship would lead to more knowledge development. 
As shown in the results section, participants' prior education had an effect on their knowledge, even when OTL in TE were taken into account. More specifically, pre-service teachers who followed an academic field of study in secondary education outperformed other pre-service teachers on PCK, PK, and CK. Pre-service teachers who studied modern languages in secondary education outperformed all others on CK. A possible explanation for this finding is that higher prior knowledge facilitates the acquisition of new knowledge. For instance, higher prior knowledge might support the integration of new knowledge into existing schemata (Blömeke et al., 2012). Future research could dig deeper into this explanation.

There are some limitations to the present study, leading to suggestions for further research. Firstly, the study approaches teachers' professional knowledge from a cognitive point of view. Although studying teacher knowledge from this perspective has many advantages (e.g., the ability to systematically study knowledge on a large scale) and the importance of declarative teacher knowledge for educational quality has been shown in several studies (Baumert et al., 2010; König \& Pflanzl, 2016; Kunter et al., 2013), a too narrow focus on a cognitive perspective might neglect what actually happens in the classroom (Depaepe et al., 2013; Stahnke et al., 2016). Therefore, future research is recommended to complement the findings of the present study with results that are more situated in the classroom, using a broader array of instruments, allowing to capture teachers' knowledge in action. Secondly, the number of hours that are provided for PCK, PK, CK, and the number of internship days are rather simplistic measures of OTL in TE. Quality of OTL probably depends more on the content that is studied in these courses than on their duration. Even though these measures have provided first insights into the effects of OTL, further research could broaden these results by using more specific measures, such as self-reports on which topics were covered during TE. However, self-reports also have their pitfalls as not all participants might be able to exactly report what OTL they encountered during their TE. Therefore, a combination of measures used in the present study and other measures seems to be the most plausible way to grasp OTL. Thirdly, our measure of PK OTL could unfortunately not be included in the tested model due to violation of the multicollinearity assumption. It would be interesting to investigate the impact of $\mathrm{PK}$ OTL in future research, for instance by using self-report measures.

In conclusion, the present study has important implications for both theory and TE. From a theoretical point of view, the study shows that, in the domain of French, the impact of OTL in teacher education is not fully similar to findings in the domain of mathematics. Whereas PCK courses promoted students' PCK and PK, CK courses only had an impact on CK. Transfer from PCK is only made to PK, not to CK. Furthermore, practical experiences did not impact students' declarative knowledge development. From a practical point of view, the present study indicates the importance of including courses on PCK and CK in TE. As the differences in teachers' professional knowledge among cohorts are not very large, it would be beneficial to provide more time for French PCK and CK, or to use the available time in a more efficient way. Furthermore, the present study shows the impact of pre-service teachers' educational background on their knowledge development during teacher education. It might be useful for TE to provide extra support for students who have less prior knowledge due to their educational background.

Acknowledgments. The authors thank Katrien Dewaele and Leen Van Craesbeek for their help with developing the instruments.

\section{References}

1. Altman, D. G. (1999). Practical statistics for medical research. New York, NY: Chapman \& Hall/CRC Press.

2. Baumert, J., Kunter, M., Blum, W., Brunner, M., Voss, T., Jordan, A., ... Tsai, Y. (2010). Teachers' mathematical knowledge, cognitive activation in the classroom, and student progress. American Educational Research Journal, 47, 133 - 180. doi: 10.3102/0002831209345157.

3. Blömeke, S., Buchholtz, N., Suhl, U., \& Kaiser, G. (2014). Resolving the chicken-or-egg causality dilemma: The longitudinal interplay of teacher knowledge and teacher beliefs. Teaching and Teacher Education, 37, 30-39. doi: 10.1016/j.tate.2013.10.007.

4. Blömeke, S., Paine, L., Houang, R.T., Hsieh, F., Schmidt, W. H., Tatto, T., ... \& Schwille, J. (2008). Future teachers' competence to plan a lesson: first results of a six-country study on the efficiency of teacher education. ZDM Mathematics Education, 40, 749-762. doi: 10.1007/s11858-008-0123-y.

5. Blömeke, S., Suhl, U., Kaiser, G., \& Döhrmann, M. (2012). Family background, entry selectivity and opportunities to learn: What matters in primary teacher education? An international comparison of fifteen countries. Teaching and Teacher Education, 28, 44-55. doi: 10.1016/j.tate.2011.08.006. 
6. Bowerman, B. L., \& O'Connell, R. T. (1990). Linear statistical models: An applied approach (2nd ed.). Belmont, CA: Duxbury.

7. Capraro, R. M., Capraro, M. M., Parker, D., Kulm, G., \& Raulerson, T. (2005). The mathematics content knowledge role in developing preservice teachers' pedagogical content knowledge. Journal of Research in Childhood Education, 20, 108-124.

8. Cochran-Smith, M., \& Zeichner, K. M. (2005). Studying teacher education: The report of the AERA panel on research and teacher education. Mahwah, NJ: Lawrence Erlbaum.

9. Connelly, F. M., Clandinin, D. J., \& He, M. F. (1997). Teachers' personal practical knowledge on the professional knowledge landscape. Teaching and Teacher Education, 13, 665-674. doi: 10.1016/S0742-051X(97)00014-0.

10.Council of Europe (n.d.). Common European framework of reference for languages: Learning, teaching, assessment. Retrieved September 21, 2016, from http://www.coe.int/t/dg4/linguistic/Source/Framework_EN.pdf.

11.Depaepe, F., Verschaffel, L., \& Kelchtermans, G. (2013). Pedagogical content knowledge: A systematic review of the way in which the concept has pervaded mathematics educational research. Teaching and Teacher Education, 34, 12-25. doi: 10.1016/j.tate.2014.12.009.

12.Fauth, B., Decristan, J., Rieser, S., Klieme, E., \& Büttner, G. (2014). Student ratings of teaching quality in primary school: Dimensions and prediction of student outcomes. Learning and Instruction, 29, 1-9. doi: 10.1016/j.learninstruc.2013.07.001.

13.Field, A. (2013). Discovering statistics using IBM SPSS Statistics. London, UK: Sage.

14.González Humanez, L. E., \& Arias, N. (2009). Enhancing oral interaction in English as a foreign language through task-based learning activities. Latin American Journal of Content \& Language Integrated Learning, 2, 19. doi:10.5294/laclil.2009.2.2.10.

15.Grossman, P. L. (1990). The making of a teacher: Teacher knowledge and teacher education. New York, NY: Teachers College Press.

16.Herazo Rivera, J. D. (2010). Authentic oral interaction in the EFL class: What it means, what it does not. PROFILE Issues in Teachers' Professional Development, 12, 47-61.

17.Hlas, A., \& Hildebrandt, S. (2010).: Spanish Liberal Arts and Spanish Education majors' writing. L2 Journal, 2 , $1-22$.

18.König, J., Blömeke, S., Paine, L., Schmidt, W. H., \& Hsieh, F.-J. (2011). General pedagogical knowledge of future middle school teachers: On the complex ecology of teacher education in the United States, Germany, and Taiwan. Journal of Teacher Education, 62, 188-201. doi: 10.1177/0022487110388664.

19.König, J., Lammerding, S., Nold, G., Rohde, A., Strauß, S., \& Tachtsoglou, S. (2016). Teachers' professional knowledge for teaching English as a foreign language: Assessing the outcomes of teacher education. Journal of Teacher Education, 67, 320-337. doi: 10.1177/0022487116644956.

20.König, J., \& Pflanzl, B. (2016). Is teacher knowledge associated with performance? On the relationship between teachers' general pedagogical knowledge and instructional quality. European Journal of Teacher Education, 39, 419-436. doi: 10.1080/02619768.2016.1214128.

21.Kleickmann, T., Richter, D., Kunter, M., Elsner, J., Besser, M., Krauss, S., \& Baumert, J. (2013). Teachers' content knowledge and pedagogical content knowledge: The role of structural differences in teacher education. Journal of Teacher Education, 64, 90-106. doi: 10.1177/0022487112460398.

22.Krauss, S., Brunner, M., Kunter, M., Baumert, J., Blum, W., Neubrand, M., \& Jordan, A. (2008). Pedagogical content knowledge and content knowledge of secondary mathematics teachers. Journal of Educational Psychology, 100, 716-725. doi: 10.1037/0022-0663.100.3.716.

23.Kunter, M., Klusmann, U., Baumert, J., Richter, D., Voss, T., \& Hachfeld, A. (2013). Professional competence of teachers: Effects on instructional quality and student development. Journal of Educational Psychology, 105, 805820. doi: $10.1037 / \mathrm{a} 0032583$.

24.Kwakernaak, E. (2009). Didactiek van het vreemdetalenonderwijs. [Didactics of foreign language education]. Bussum, the Netherlands: Coutinho.

25.Lim-Teo, S.K., Chua, K.G., Cheang, W.K. \& Yeo, J.K.K. (2007). The development of diploma in education student teachers' mathematics pedagogical content knowledge. International Journal of Science and Mathematics Education, 5, 237-261.

26.Magnusson, S., Krajcik, J., \& Borko, H. (1999). Nature, sources and development of pedagogical content knowledge for science teaching. In J. Gess-Newsome \& N. G. Lederman (Eds.), Examining pedagogical content knowledge (pp. 95 - 132). Dordrecht, the Netherlands: Kluwer Academic Publishers. 
27.Martens, L., \& Voets, E. (2012). Hoe 'stERK' is het Frans van de beginnende studenten Bachelor Lager Onderwijs? [How strong is the French level of beginning students in primary school teacher education?] Tijdschrift voor lerarenopleiders (VELON/VELOV), 33, 57-66.

28.Pigge, F.L., \& Marso, R.N. (1997). A seven-year long multi-factor assessment of teaching concerns development through preparation and early years of teaching. Teaching and Teacher Education, 13, 225 - 235.

29.Qian, H., \& Youngs, P. (2016). The effect of teacher education programs on future elementary mathematics teachers' knowledge: a five-country analysis using TEDS-M data. Journal of Mathematics Teacher Education, 19, 371-396. doi: 10.1007/s10857-014-9297-0.

30.Schmidt, W. H., Cogan, L., \& Houang, R. (2011). The role of opportunity to learn in teacher preparation: An international context. Journal of Teacher Education, 62, 138-153. doi: 10.1177/0022487110391987.

31.Sercu, L., Vyncke, C., \& Peters, E. (2003). Testen en evalueren in het vreemdetalenonderwijs [Assessment and evaluation in foreign language education]. Mechelen: Plantyn.

32.Shulman, L. S. (1986). Those who understand: Knowledge growth in teaching. Educational Researcher, $15,4-14$.

33.Shulman, L. S. (1987). Knowledge and teaching: Foundations of the new reform. Harvard Educational Review, $57(1), 1-22$

34.Stahnke, R., Schueler, S., \& Roesken-Winter, B. (2016). Teachers' perception, interpretation, and decisionmaking: A systematic review of empirical mathematics education research. ZDM Mathematics Education, 48, 1-27. doi: 10.1007/s11858-016-0775-y.

35.Strawhecker, J. (2005). Preparing elementary teachers to teach mathematics: How field experiences impact pedagogical content knowledge. Issues in the Undergraduate Mathematics Preparation of School Teachers, 4, 1-12.

36.Stürmer, K., Könings, K. D., \& Seidel, T. (2013). Declarative knowledge and professional vision in teacher education: Effect of courses in teaching and learning. British Journal of Educational Psychology, 83, 467-483. doi:10.1111/j.2044-8279.2012.02075.x.

37.Theissen, S., Hiligsmann, P., Rasier, L., \& Klein, C. (2015). Nederlands-Frans in contrast, 2000 lexicologische valstrikken in het Frans [Dutch-French in contrast, 2000 lexicological pitfalls in French]. Leuven, Belgium: Acco.

38.Verloop, N., van Driel, J. H., \& Meijer, P. (2001). Teacher knowledge and the knowledge base of teaching. International Journal of Educational Research, 35, 441-461. doi: 10.1016/S0883-0355(02)00003-4.

39.Voss, T., Kunter, M., \& Baumert, J. (2011). Assessing teacher candidates' general pedagogical/psychological knowledge: Test construction and validation. Journal of Educational Psychology, 103, 952-969. doi: $10.1037 / \mathrm{a} 0025125$.

40.Watzke, J.L. (2007). Foreign language pedagogical knowledge: Toward a developmental theory of beginning teacher practices. The Modern Language Journal, 91, 63-82. 